\title{
Posterior lumber interbody fusion with pedicle screw fixation for the management of spondylolisthesis: An analysis of 40 cases
}

\author{
Md. Rezaul Amin, Md. Atikur Rahman, Akhlaque Hossain Khan, Haradhan Devnath, \\ A. B. M. Manwar Hossain, Motashimul Hasan and Kanak Kanti Barua
}

\section{Article Info \\ Department of Neurosurgery, Faculty of Surgery, Bangabandhu Sheikh Mujib \\ Medical University, Shahbag, Dhaka, \\ Bangladesh \\ For Correspondence: \\ Md Rezaul Amin \\ rezaul_amin@yahoo.com \\ Received: \\ Accepted: \\ Available Online: \\ 23 August 2017 \\ 1 September 2017 \\ 3 September 2017}

ISSN: 2224-7750 (Online)

2074-2908 (Print)

DOI: 10.3329/bsmmuj.v10i3.33699

Cite this article:

Amin MR, Rahman MA, Khan AH, Devnath $\mathrm{H}$, Hossain $A B M M$, Hasan $M$, Barua KK. Posterior lumber interbody fusion with pedicle screw fixation for the management of spondylolisthesis: An analysis of 40 cases. Bangabandhu Sheikh Mujib Med Univ J. 2017; 10: 147150.

\section{Copyright:}

The copyright of this article is retainted

by the author(s) [Atribution CC-By 4.0]

\section{Available at:}

www.banglajol.info

A Journal of Bangabandhu Sheikh Mujib Medical University, Dhaka, Bangladesh

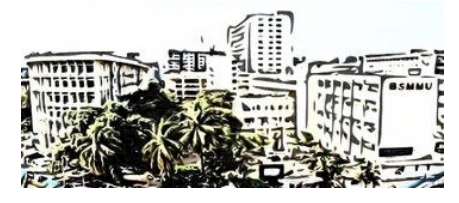

\section{Abstract}

Spondylolisthesis is forward slipping of upper vertebra in relations to its lower one, commonest is L4-L5. The ideal surgical treatment of spondylolisthesis is still controversial. Posterior lumber interbody fusion with pedicle fixation is one of treatment choices for the lumber spondylolisthesis. Forty patients who operated through posterior lumber interbody fusion and pedicle screw fixation by single surgeon was included from January 2012 to March 2015. Periodical follow-up was done both clinically and radiologically up to 6 months. Patient outcome was completed based on pain relief graphic rating scale and Oswestry disability index. In our series, the excellent outcome were 25 patients $(62.5 \%)$, good were 12 patients $(30 \%)$, and fair were 3 patients $(7.5 \%)$. There were no poor outcome and no new neurological deficit. This study concludes that posterior lumber interbody fusion with pedicle is an effective treatment for the lumber spondylolisthesis. It helps to maintain the biomechanics, associated with less complication and improve the quality of life of patient.

\section{Introduction}

Spondylolithesis is forward slipping of upper vertebra in relation to its lower one which is classified by Wiltse and Rothman into dysplastic, ishtmic, degenerative, traumatic, pathologic and iatrogenic. 1 The degree of slip is measured with Meyerding Grades into I, II, II, IV and V or spondyloptosis.? Meyerding Grade I and II are low and Meyerding Grade 3, 4, or 5 are high. 3 Spondylolishesis always represent the mechanism of spinal instability. $\underline{4}$ It may be due to ligamentous laxity, a defect in the pars interarticularis, previous surgery, or may be traumatic and up to $5 \%$ of the general population suffer from spondylolisthesis and it can occur at any age. $\frac{5}{-}$

Indication for surgery of spondylolisthesis is intolerable due to low back pain, severe radicular pain, neurogenic claudication, presence of neurological symptoms, conservative treatment failure, increase grading of listhesis, instability confirmed by radiology, Meyerding Grade III and IV listhesis, and spondyloptosis.2,5,6 The ideal surgical treatment remains controversial. 7,8

Several procedures have been described in the surgical management of spondylolisthesis where the fusion with or without instrumen- tation is the most popular. Anterior lumbar interbody fusion, posterior lumbar interbody fusion, posterior lumber fusion, circumferential 360 fusion (front and back) and more recently, the transforaminal lumbar interbody fusion are the most common procedure done in lishesis. $\frac{9}{9}$

Lumbar interbody fusion is the most reliable and popular fusion technique because it is biomechanically stronger, provide axial support with less graft subsidence or collapse comparing to those with posterolateral arthrodesis, and produce a better biologic fusion in lordotic alignment.10 In lumber spondylolisthesis, pedicle screw fixation was popularized in Europe in 1970 by Roy-Camille. 6 The use of posterior intersomatic fusion with autologous bone in the discal space was described by Briggs and Milligan.11 Coward popularized this procedure in 1953.12 The association of intersomatic lumber fusion with spacer and pedicle screw fixation was first proposed by Steffe. 10 In isthmic spondylolisthesis, Suk et al. used the bone graft as intersomatic spacer with the pedicle screw fixation, to provide a truly circumferential fusion with better results. $\underline{13}$

This study was conducted to share our experience with the posterior lumber interbody fusion with pedicle screw fixation for the management of lumber spondylolisthesis with its functional 


\begin{tabular}{|c|c|c|c|}
\hline \multicolumn{2}{|l|}{ Tal } & \multicolumn{2}{|c|}{$\begin{array}{l}\text { outcome and complication and compare th } \\
\text { study to other literatures. }\end{array}$} \\
\hline \multicolumn{2}{|c|}{$\begin{array}{l}\text { Patient characteristic } \\
\qquad(\mathrm{n}=40)\end{array}$} & & \\
\hline \multicolumn{2}{|l|}{ Age (Years) } & \multicolumn{2}{|c|}{ Materials and Methods } \\
\hline $21-30$ & 2 & \\
\hline \multicolumn{2}{|l|}{$31-40$} & \multirow{4}{*}{\multicolumn{2}{|c|}{$\begin{array}{l}\text { Forty patients who diagnosed as lumber } \\
\text { spodylolisthesis treated with posterior lumber } \\
\text { interbody fusion and pedicle screw fixation } \\
\text { during the period of January } 2012 \text { to March } 2015 \\
\text { done by a single surgeon was included in this }\end{array}$}} \\
\hline \multicolumn{2}{|l|}{$41-50$} & & \\
\hline \multicolumn{2}{|l|}{$51-60$} & & \\
\hline \multicolumn{2}{|l|}{$61-70$} & & \\
\hline \multicolumn{2}{|c|}{ Spondylolishthesis } & \\
\hline Degenerative & 25 & \multirow{3}{*}{\multicolumn{2}{|c|}{$\begin{array}{l}\text { unwilling to do the operation, pathological } \\
\text { spondylolisthesis and treated conservatively } \\
\text { were excluded in this study. A proforma was }\end{array}$}} \\
\hline \multicolumn{2}{|l|}{ Isthmic } & & \\
\hline \multicolumn{2}{|l|}{ Traumatic } & & \\
\hline \multicolumn{2}{|l|}{ Involved level } & \multirow{3}{*}{\multicolumn{2}{|c|}{$\begin{array}{l}\text { made for each patient and records were kept in } \\
\text { a custom built Microsoft Excel Database. The } \\
\text { consent was obtained from each patient. }\end{array}$}} \\
\hline \multicolumn{2}{|l|}{ L4 - L5 } & & \\
\hline \multicolumn{2}{|l|}{ L5 - S1 } & & \\
\hline \multicolumn{2}{|l|}{ L3 - L4 } & \multirow{2}{*}{\multicolumn{2}{|c|}{ There were 22 females and 18 males patie }} \\
\hline \multicolumn{2}{|l|}{ L3 - L4 - L5 } & & \\
\hline \multicolumn{2}{|l|}{ L4 - L5 - S1 } & \multicolumn{2}{|c|}{$\begin{array}{l}\text { The mean age of the patients in the study was } \\
41.4 \text { years with maximum patients being in the }\end{array}$} \\
\hline \multicolumn{2}{|c|}{ Grading (Meyerding) } & \multirow{2}{*}{\multicolumn{2}{|c|}{$\begin{array}{l}41.4 \text { years with maximum patients being in the } \\
41-60 \text { age groups ( } 25 \text { patients). }\end{array}$}} \\
\hline Grade 1 & 20 & & \\
\hline Gro & 14 & \multirow{2}{*}{\multicolumn{2}{|c|}{$\begin{array}{l}\text { Preoperatively all patients had the plain radic } \\
\text { graphs of lumbosacral spine that include }\end{array}$}} \\
\hline $\mathrm{Gr}$ & 5 & & \\
\hline Grade 4 & 1 & antero-po & $\begin{array}{l}\text { rior, lateral, bilateral oblique, } \mathrm{f} \\
\text { ion and extension dynamic vie }\end{array}$ \\
\hline & II & & $\begin{array}{l}\text { The assessment of cauda } \\
\text { and nerve root was carrie }\end{array}$ \\
\hline Pain relie & phic ra & ing scale) & in all the cases. The pe \\
\hline Pain (GRS) & $\begin{array}{l}\text { Pre- } \\
\text { perative }\end{array}$ & $\begin{array}{l}\text { Post- } \\
\text { operative }\end{array}$ & $\begin{array}{l}\text { slip was graded according } \\
\text { Meyerding's (Figure 1, Figure 2). }\end{array}$ \\
\hline No pain & 0 & 28 & The major ind \\
\hline Mild & 1 & 6 & \\
\hline Moderate & 3 & 5 & back or leg pain, severe neurog \\
\hline Severe & 31 & 1 & claudication leading to a signifi \\
\hline Excruciating & 5 & 0 & reduction in the quality of \\
\hline
\end{tabular}

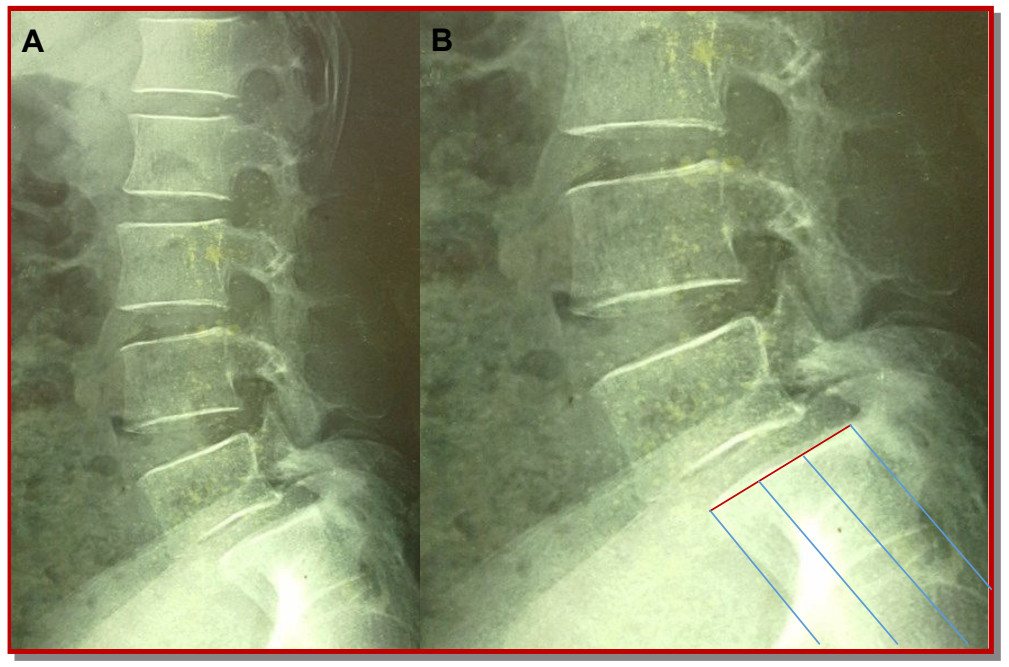

Figure 1: X-ray lateral view (A); X-Ray lumbosacral spine lateral view showing Grade 1 spondylolisthesis of L4/L5 in a case of 40 years male (B), Red marked scale show the measurement of grading of slip treatment, and worsening neurological deficit with bowel/bladder involvement.

After thorough investigation and obtaining fitness for the surgery from both the medical and anesthetic teams, all 40 patients with spondylolisthesis underwent posterolumber interbody fusion with bone grafting from the spine and lamina of the same vertebra and posterior spinal instrumentation with the pedicle screws and rods under general anesthesia (Figure 3, Figure 4).

The patients received intravenous antibiotics for a minimum of 5 days. Mobilization was commenced on the $5^{\text {th }}$ post-operative day with a lumbosacral corset. In the meanwhile patients underwent bedside physiotherapy in the form of deep breathing exercises, active and passive limb range of motion exercises. The patients were reviewed periodically after discharge at 6th, 12th weeks and at 6th months. The results were analyzed in the forms of union, reduction of lysthesis and clinical improvement in complaints of back pain, claudication pain and neurological deficits. Follow-up radiographs were obtained at all the outdoor visits to determine the amount of fusion and implant position. Graphic rating scale using descriptive terms such as mild, moderate, severe and pain as bad as it could be (excruciating) was used as a tool to describes patients pain pre- and post-operatively.

Data was collected based on the Oswestry disability index $\underline{14}$ as following: Excellent outcome: No more pain or neurological deficits was included in this group. Patient's satisfaction was more than $80 \%$ with normal daily activities. Good outcome: Back pain and sciatica were significantly improved, analgesics were required some times and less experience with numbness and paraesthesia and improve in weakness was noticeable. No constraint in daily activities any more with satisfaction of the patient was $60-80 \%$. Fair outcome: Compared with the pre-operative status improvement was up to $50 \%$ but strong analgesics needed occasionally, improvement in sensory and motor symptoms was evident mild but daily activities of the patient had some difficulty. Patient's satisfaction was around 50 - $60 \%$. Poor outcome: Symptoms compared with pre -operatively was same or worsened up. Patient had significant restriction of their daily life activities.

\section{Results}

Degenerative listhesis was more common 25 (62.5\%) and the more common involved level was L4-L5, L5 -S1 was the second commonest (30\%) (Table I). Slip grade was measured with Meyerding scale, 20 patients had Grade 1 and 14 patients had Grade 2.

Pain is the main indication for surgery. Severe pain was in 31 cases and excruciating in 5 cases (Table II). Thirty eight patients had neurogenic claudica- 


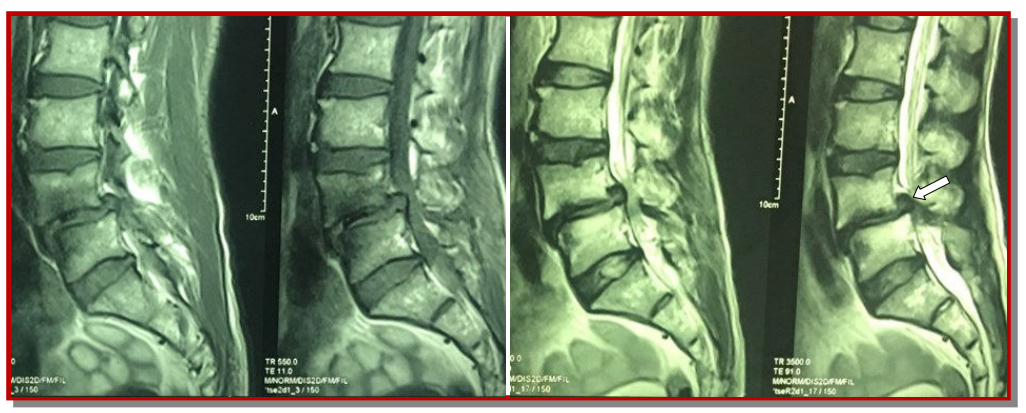

Figure 2: MRI of Grade 1 spondylolisthesis of L4/L5 of 40 years old male (arrow indicates)

\begin{tabular}{|c|c|c|c|}
\hline \multicolumn{3}{|c|}{ Table III } & audication po \\
\hline \multicolumn{3}{|c|}{$\begin{array}{l}\text { Clinical outcome } \\
\text { (Oswestry disabil- } \\
\text { ity index) }\end{array}$} & $\begin{array}{l}\text { meter. Twenty eight patient } \\
\text { gery which was improved si }\end{array}$ \\
\hline Result & $\mathrm{n}$ & $(\%)$ & pain. Bo \\
\hline Excellent & & 62.5 & \\
\hline Good & & 30 & e maintained by doing self-catheterization. \\
\hline $\mathrm{Fa}$ & & 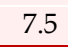 & -up was s antu o mintitu \\
\hline
\end{tabular}

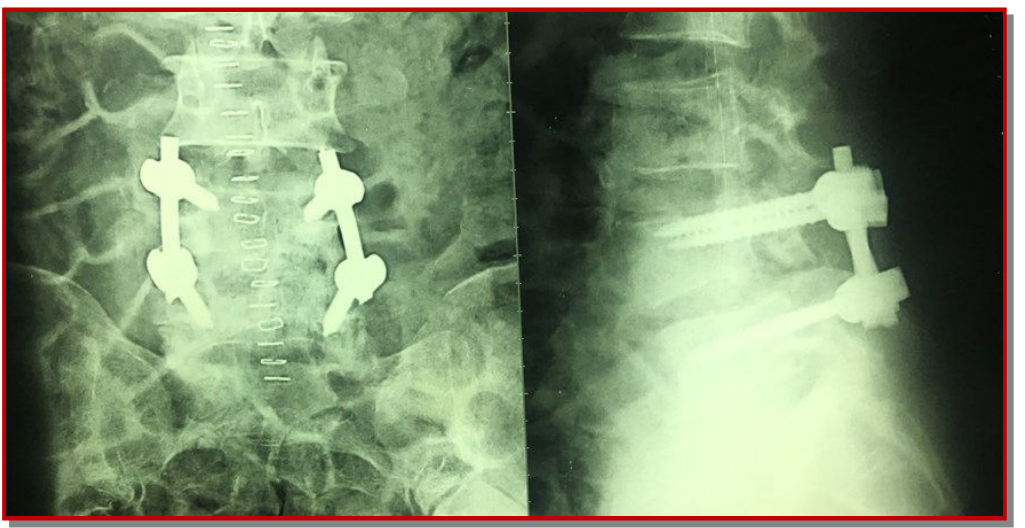

Figure 3: Post-operative X-ray of L4/L5 listhesis

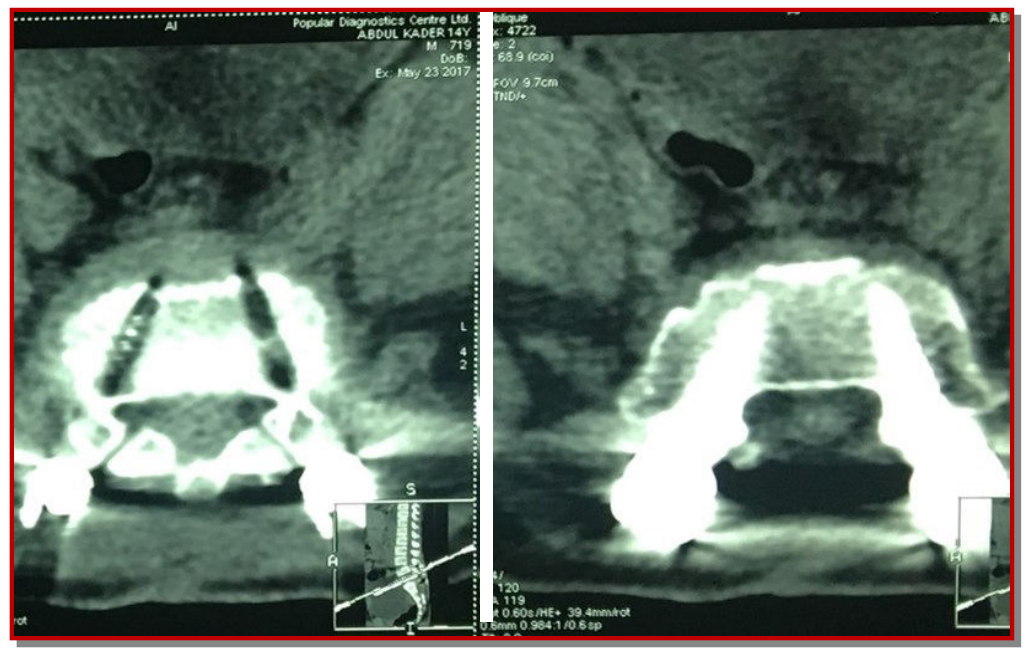

Figure 4: CT scan shows position of screw after fixation was achieved in 34 cases. Only 2 had hardware failure, 1 developed psudoarthrosis. We had dural tear of 2 patients, which was repaired at the time of operation, 1 patient had post-operative wound infection which was treated accordingly. Medical problem such as urinary tract infection and pneumonia developed in 2 patients. Clinical outcome were measured by Oswestry disability index, excellent were 25 patients $(62.5 \%)$, good were 12 patients $(30 \%)$ and fair were 3 patients (7.5\%) (Table III).

\section{Discussion}

In this study, the average age incidence were 41.4 years, which was similar to the Madan and Boeree et al (44.4 years) $\underline{15}$ and Kim et al (41.3 years). .16 Among 40 patients of this study, majority of them are $4^{\text {th }}$ and $5^{\text {th }}$ decade, with slight female preponderance 22 female (55\%) and 18 male (45\%). The female predominance may be attributed to repeated birth trauma, tendency to obesity, weak musculature and osteoporosis. 17 The most common affected level in this series was L4-L5 level $(50 \%)$ and Grade 1 spodylolisthesis in Meyerding2 scale is more common $(50 \%)$. Fifty percent were defective levels were reported by Kim et al. and was found same in our series.

In this study, conservative trial including bed rest, anti-inflammatory drugs, physiotherapy and bracing was tried in all patients. This was the same with Cheng et al. (1989).18 Surgical indications, in this study, were intractable pain not responding to conservative treatment, neurological deficits including sensory, motor or reflex changes, bowelbladder symptoms and slip progression. Cheng et al. (1989) and Burkus et al. (1992) and reported same indications for surgical intervention. $\underline{18,19}$ We achieved pain relief in $70 \%$ patients.

The clinical outcome in spondylolisthesis is closely related to the attainment of solid fusion. 20 In this series we achieved fusion at 6 month follow-up to $85 \%$ patients, which was similar to Madan and Boeree et al (87.5\%)므 and Kim et al (95\% )..

In this series we hardware failure of $2(5 \%)$ patients, regarding one patient had one screw breakage and other developed pseudoarthrosis. We had unintended dural tear of $2(5 \%)$ patients, which was repair by simple stich. We had wound infection of 1 $(2.5 \%)$. This was improved by daily dressing and proper antibiotics. Dickman et al. (1992) and West et al. (1991) reported infection rate range from $0-6 \% . \underline{21}$, $\underline{22}$

Good outcome was significantly associated with younger age group, male gender, lower grade of slip and radiological fusion group. However, final outcome had no significant relation between the level of instability. In spondylolisthesis patients for 
proper surgical management, the main key was to know the concern biomechanics of that level. We measure the clinical outcome by Oswestry disability index. $35(87.5 \%)$ patients had excellent and good outcome, which was almost same when compared to study of Kim et al (90\%)프 and slightly more than Madan and Boeree et al (81\%). 15 Three patients had fair outcome, which may be due to late presentation, severe claudication pain and neurological deficit at time of initial presentation, hamstring spasm/sciatica and poor patient's compliance with post-operative physiotherapy and follow-up.

\section{Conclusion}

Posterior lumber interbody fusion with pedicle screw fixation is the effective treatment of lumber spodylolisthesis. It helps to maintain the biomechanics, correct the deformity, maintaining the spinal angulation, thus prevent the further neurological deficit, associated with less complication and improve the quality of life of patient.

\section{References}

1. Wiltse LL, Newman PH, Macnab I. Classification of spondylolisis and spondylolisthesis. Clin Orthop Relat Res. 1976; 117: 23-29.

2. Meyerding HW. Spondylolisthesis. Surg Gynecol Obstet. 1932; 54: 371-80.

3. Bridwell KH. Surgical treatment of high-grade spondylolisthesis. Neurosurg Clin N Am. 2006; 17: 331-38.

4. Dantas FL, Prandini MN, Ferreira MA. Comparison between posterior lumbar fusion with pedicle screws and posterior lumbar interbody fusion with pedicle screws in adult spondylolisthesis. Arq Neuropsiquiatr. 2007; 65: 764-70.

5. Frymoyer JW, Selby DK. Segmental instability, Rational for treatment. Spine 1985; 15: 1216-26.

6. Roy-Camille R, Demeulenaere C. Osteosynthese du rachis dorsal, lombaire et lombo-sacre par plaques metalliqyes vissees dans less pedicules vertebraux et les apophyses articulaires. Presse Med. 1970; 78: 1447-50.

7. Zdeblick TA. A prospective, randomized study of lumbar fusion. Spine 1993; 18: 983-91.

8. Dai LY, Jia LS, Yuan W. Direct repair of defect in lumbar spondylolysis and mild isthmic spondylolisthesis by bone grafting, with or without joint fusion. Eur Spine J. 2001; 10: 78-83.
9. Feffer HL, Wiesel SW, Cuckler JM, Rothman RH. Degenerative spondylolisthesis: To fuse or not to fuse. Spine 1985; 10: 78-83.

10. Enker P, Steffee AD. Interbody fusion and instrumentation. Clin Orthop Relat Reser. 1994; 300: 90 91.

11. Evans JH. Biomechanics of lumbar fusion. Clin Orthop Relat Reser. 1985; 193: 38-46.

12. Briggs DS, Milligan PR. Chip fusion of the low back following exprolation of the spinal canal. J Bone Joint Surg (Am). 1944; 26: 125-30.

13. Suk S, Lee CK, Kim W, Lee J, Cho K. Adding posterior lumbar interbody fusion to pedicle screw fixation and posterior fusion after decompression in spondillytic spondylolisthesis. Spine 1997; 22 210-20.

14. Fairbank JCT, Pynsent, PB. The Oswestry disability index. Spine 2000; 25: 2940-53.

15. Madan S, Boeree NR. Outcome of posterior lumbar interbody fusion versus posterolateral fusion for spondylolytic spondylolisthesis. Spine 2002; 27: 1536-42.

16. Kim EH, Kim HT. En bloc partial laminectomy and posterior lumbar interbody fusion in foraminal spinal stenosis. Asian Spine J. 2009; 3: 66-72.

17. Peek RD1, Wiltse LL, Reynolds JB, Thomas JC, Guyer DW, Widell EH. In situ arthrodesis without decompression for Grade-III or IV isthmic spondylolisthesis in adults who have severe sciatica. J Bone Joint Surg Am. 1989; 71: 62-68.

18. Cheng CL, Fang D, Lee PC, Leong JC. Anterior spinal fusion for spondylolysis and isthmic spondylolisthesis. Long-term results in adults. J Bone Joint Surg Br Mar. 1989; 71: 264-67.

19. Burkus JK, Lonstein JE, Winter RB, Denis F. Longterm evaluation of adolescents treated operatively for spondylolisthesis: A comparison of in situ arthrodesis only with in situ arthrodesis and reduction followed by immobilization in a cast. J Bone Joint Surg Am. 1992; 74: 693-704.

20. Girardo M, Bettini N, Dema E, Cervellati S. Uninstrumented posterolateral spinal arthrodesis: Is it the gold standard technique for I degrees and II degrees grade spondylolisthesis in adolescence? Eur Spine J. 2009; 18: 126-32.

21. Dickman CA1, Fessler RG, MacMillan M, Haid RW. Transpedicular screw-rod fixation of the lumbar spine: Operative technique and outcome in 104 cases. J Neurosurg. 1992; 77: 860-70.

22. West JL 3rd, Bradford DS, Ogilvie JW. Results of spinal arthrodesis with pedicle screw-plate fixation. J Bone Joint Surg Am. 1991; 73: 1179-84. 